\section{PENICILLIN SULPHOXIDE METABOLITE: X-RAY STRUCTURE OF A NOVEL 1,4-DIHYDROTHIAZINE-CONTAINING DERIVATIVE}

Sir:

Penicillin V $\beta$-sulphoxide (1) was recently reported to undergo degradation by extracellular enzymes of bacteria and streptomycetes to an unstable metabolite (PSM), which on sequential treatment with acetyl chloride and $\mathrm{CH}_{2} \mathrm{~N}_{2}$ yielded an ester, $\mathrm{C}_{28} \mathrm{H}_{28} \mathrm{O}_{7} \mathrm{~N}_{3} \mathrm{~S}$, m.p. $174^{\circ} \mathrm{C}$. ${ }^{1)}$ This ester was assigned the 1,4-dihydrothiazine structure (2), primarily on the basis of spectroscopic data, which led to the provisional structure (3) for PSM, requiring an intermolecular reaction of two molecules of $\mathbf{1}$ with the hydrolysis of both penam N(4)-C(7) bonds and one $\mathrm{C}(5)-\mathrm{C}(6)$ bond.

In view of the key structural significance of this ester it has been subjected to an X-ray crystallographic analysis which confirmed the structure (2) and established the conformation shown in the figure.

Initial attempts at an X-ray solution were hampered by the tendency of the ester to form twinned crystals, and a suitable single crystal was only obtained after removal of the twinned component by careful sectioning under the microscope.

Crystals of 2 are triclinic, $a=14.593(3), b=$ 11.476(2), $\quad c=8.916(2) \AA, \quad \alpha=118.33(2), \quad \beta=$ 92.30(3), $\gamma=94.37(3)^{\circ}, U=1306 \AA^{3}$; space-group $\mathrm{P} \overline{\mathrm{i}}, \mathrm{Z}=2, \mathrm{D}_{\mathrm{c}}=1.35 \mathrm{gcm}^{-3}$. A total of 3292 reflections (2437 observed) were measured on a diffractometer $\left(\theta \leq 55^{\circ}\right)$ using $\mathrm{CuK}_{\alpha}$ radiation. The structure (Fig. 1) was solved by direct methods and refined to give $R=0.052^{*}$.

Symmetry-related molecules are linked to form a continuous chain by intermolecular $\mathrm{N}-\mathrm{H}---\mathrm{O}$ hydrogen bonds between the amide groups of the phenoxyacetamido and phenoxyacetylglycyl substituents $(2.80,2.90 \AA)$. Within each molecule the close proximity of both amide nitrogens to their adjacent phenoxy oxygens $(2.60,2.69 \mathrm{~A})$, is indicative of intramolecular bonding between these two groups. This cis orientation of the pairs of oxygen and nitrogen atoms contrasts with the trans arrangement observed in $\mathbf{4}^{2}$. In the dihydrothiazine ring of $\mathbf{2}$, only the carbomethoxy-substituted carbon $\mathrm{C}(3)$ is appreciably out of plane $(0.6 \AA)$. The large torsional twist $\left(36^{\circ}\right)$ about the bond linking the dihydrothiazine to its phenoxyacetamido substituent

Fig. 1.

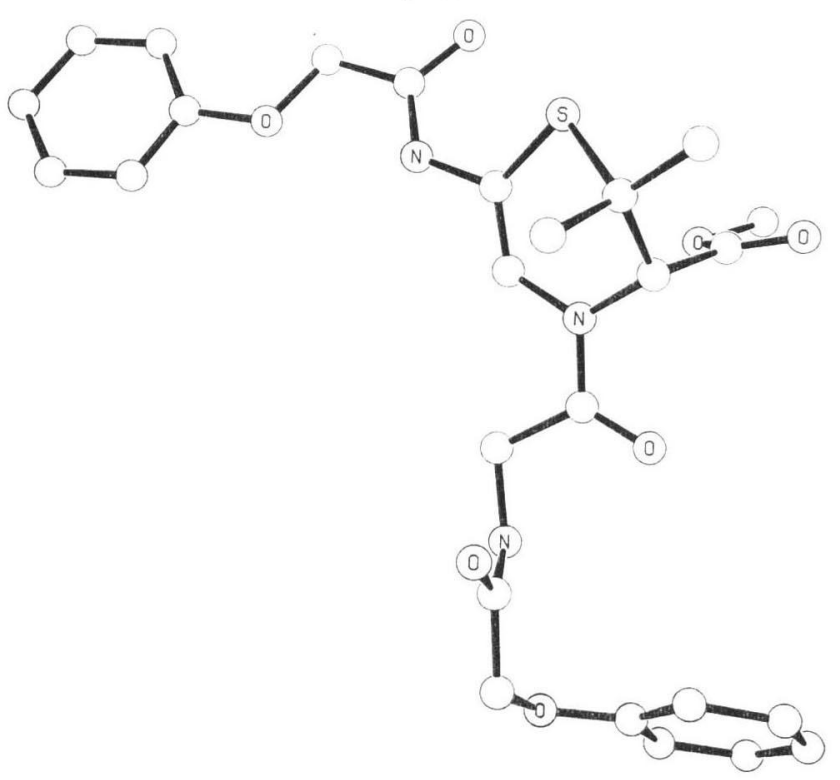

* The atomic coordinates for this work are available on request from the Director of the Cambridge Crystallographic Data Centre, University Chemical Laboratory, Lensfield Road, Cambridge CB2 1EW, U.K. Any request should be accompanied by the full literature citation for this communication. 


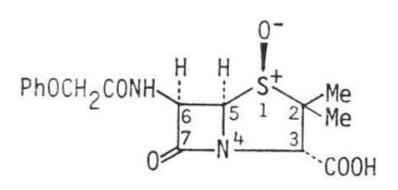

(1)

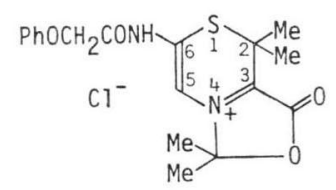

(4)

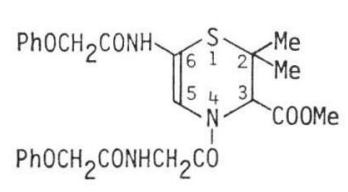

(2)

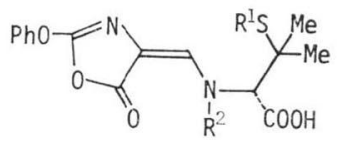

$\mathrm{R}_{1} \quad \mathrm{R}_{2}$

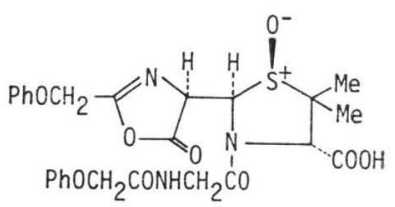

(3)

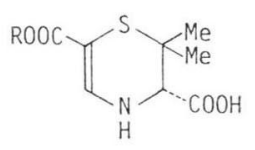

(7) $\mathrm{R}=$ enzyme

(5) $\mathrm{AcO} \mathrm{PhOCH}_{2} \mathrm{CONHCH}_{2} \mathrm{CO}$

(6) $\mathrm{H} \quad \mathrm{H}$

at $\mathrm{C}(6)$ reflects a loss of conjugation between the ring double bond and this amide.

Formation of the phenoxyacetylglycyl substituent of 2 requires a double cleavage of the parent $\beta$-lactam ring, analogous to that involved in the slow conversion of penicillins $\mathrm{G}$ and $\mathrm{V}$ to the corresponding acylglycines by their target enzymes, which catalyse the crosslinking of the bacterial cell wall peptidoglycan. However, the extracellular bacterial enzymes which were observed to rapidly degrade penicillin $\mathrm{V}$ sulphoxide but not the corresponding cephalosporin sulphoxide $^{1)}$, have also been shown to readily hydrolyse the parent penicillin, indicative of normal penicillinase ( $\beta$-lactam amidohydrolase, E.C. 3.5.2.6.) activity. This is consistent with the subsequent observation (LEONG and THOMAS, to be published) that the sulphoxide (1) is metabolised by partially purified $E$. coli R46 $\beta$ lactamase $^{3,4)}$ to a mixture of products apparently including PSM, which could similarly be converted to crystalline 2 .

It follows that the $\beta$-lactamase can either effect a $\mathrm{C}(5)-\mathrm{C}(6)$ cleavage of the sulphoxide (1) or alternatively convert it to a labile intermediate in which this bond is susceptible to cleavage on mild treatment with an acyl chloride and $\mathrm{CH}_{2} \mathrm{~N}_{2}$, as in the formation of $\mathbf{2}$. A suggested mechanism for the enzymic hydrolysis of this $\beta$-lactam bond invokes prior $\mathrm{S}(1)-\mathrm{C}(5)$ cleavage of the penam thiazolidine ring, leading to $3^{1)}$. This could yield the 1,4-dihydrothiazine 2 , following cyclisation of an intermediate vinologous urethane oxazolone sulphenate 5 corresponding to the penicillenic acid $\mathbf{6}$, with loss of $\mathrm{CO}_{2}$.
A $\beta$-lactamase mediated $S(1)-C(5)$ cleavage is also implicit in the rapid irreversible inhibition of the Bacillus cereus $\beta$-lactamase I by $6 \beta-$ bromopenicillanic acid, which forms a stable, 1,4-dihydrothiazine ester 7 involving the serine44 residue of this enzyme ${ }^{5)}$. Its stability may conceivably reffect the absence in the inhibitor molecule of a 6-acylamido substituent capable of displacing the serine via an oxazolinone. This would be analogous to the proposed transformation of 1 to $3^{1)}$ with intermediate conversion of the $\beta$-lactam to a serine ester.

A further example of the enzymic $C(5)-C(6)$ cleavage of penicillin $G$ to phenylacetylglycine has recently been described, involving penicillinbinding proteins which are apparently devoid of DD-carboxypeptidase or transpeptidase activity ${ }^{6)}$.

\section{ROBERT THOMAS*}

Chemistry Department, University of Surrey, Guildford, Surrey GU2 5SX, U.K.

\section{David J. Williams}

Chemical Crystallography Laboratory, Imperial College,

London SW7 2AY, U.K.

(Received September 16, 1980)

\section{References}

1) Thomas, R.: The microbial metabolism of penicillin $\mathrm{V}$ sulphoxide and its possible relevance to the mode of action of penicillin. J. Chem. Soc. Chem. Comm. 1979: 1176 1177, 1979 
2) Thomas, R. \& D. J. Williams: Novel ring expansion product of penicillin $\mathrm{V} \beta$-sulphoxide: X-Ray crystal structure of 3,8-dihydro-3,3,8,8tetramethyl-6-phenoxyacetamido-1-oxo-oxazolo[4,3-c][1,4]thiazinium chloride. J. Chem. Soc. Chem. Comm. 1973: 226 227, 1973

3) Dale, J. W. \& J. T. Smith: The purification and properties of the $\beta$-lactamase specified by the resistance factor R-1818 in Escherichia coli and Proteus mirabilis. Biochem. J. 123: 493 500, 1971

4) Dale, J. W.: Purification of $\beta$-lactamases. In: J. M. T. Hamilton-Miller \& J. T. Smith (eds.): Beta-Lactamases. pp. 73 98, Academic Press, London, 1979
5) Orlek, B.S.; P.G. Sammes, V. Knott-Hunziker \& S. G. WAlEy: On the chemistry of $\beta$-lactamase inhibition by $6 \beta$-bromopenicillanic acid. J. Chem. Soc. Perkin I 1979: 2322 2329, 1980 Cohen, S. A. \& R. F. Pratt: Inactivation of Bacillus cereus $\beta$-lactamase I by $6 \beta$-bromopenicillanic acid: mechanism. Biochemistry 19: $3996 \sim 4003,1980$

6) Waxman, D. J. \& J. L. Strominger: Cephalosporin-sensitive penicillin-binding proteins of Staphylococcus aureus and Bacillus subtilis active in the conversion of $\left[{ }^{14} \mathrm{C}\right]$ penicillin $\mathrm{G}$ to $\left[{ }^{14} \mathrm{C}\right]-$ phenylacetylglycine. J. Biol. Chem. 254: 12056 12061, 1979 